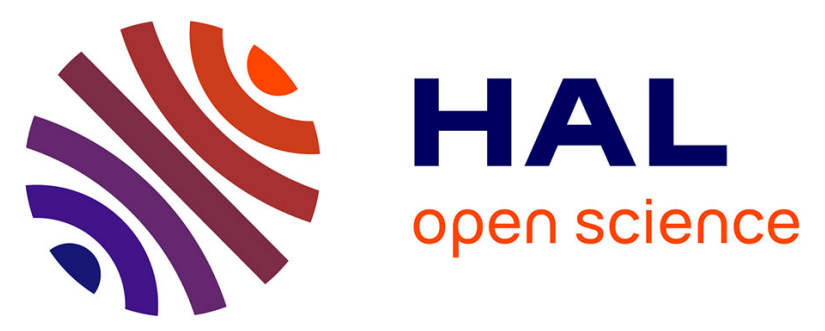

\title{
Information-sharing practices on Facebook during the 2017 French presidential campaign: An "unreliable information bubble" within the extreme right
}

Julien Figeac, Nikos Smyrnaios, Tristan Salord, Guillaume Cabanac, Ophélie

Fraisier, Pierre Ratinaud, Fanny Seffusatti

\section{To cite this version:}

Julien Figeac, Nikos Smyrnaios, Tristan Salord, Guillaume Cabanac, Ophélie Fraisier, et al.. Information-sharing practices on Facebook during the 2017 French presidential campaign: An "unreliable information bubble" within the extreme right. Communications, 2020, 45 (s1), pp.648-670. 10.1515/commun-2019-0193 . halshs-02967512

\section{HAL Id: halshs-02967512 \\ https://shs.hal.science/halshs-02967512}

Submitted on 15 Oct 2020

HAL is a multi-disciplinary open access archive for the deposit and dissemination of scientific research documents, whether they are published or not. The documents may come from teaching and research institutions in France or abroad, or from public or private research centers.
L'archive ouverte pluridisciplinaire HAL, est destinée au dépôt et à la diffusion de documents scientifiques de niveau recherche, publiés ou non, émanant des établissements d'enseignement et de recherche français ou étrangers, des laboratoires publics ou privés. 
Julien Figeac*, Nikos Smyrnaios, Tristan Salord, Guillaume Cabanac, Ophélie Fraisier, Pierre Ratinaud and Fanny Seffusatti

\title{
Information-sharing practices on Facebook during the 2017 French presidential campaign: An "unreliable information bubble" within the extreme right
}

https://doi.org/10.1515/commun-2019-0193

\begin{abstract}
This research explores the spread of unreliable information on Facebook during the 2017 French presidential campaign. By analyzing information-sharing behavior on 252 Facebook pages, our study highlights the wide variety of information sources shared by several political communities, notably news published by partisan websites or activist blogs. Our results demonstrate that political parties - particularly, those on the extreme ends of the political spectrum - tend to re-share a large amount of information reflecting the same ideological positions as their own. This trend is amplified by a phenomenon of endo-citation, that is, a "circular circulation" of information between Facebook pages within the same political community. Our results focus on the information practices of the far-right, tracing a clear over-representation of sources that are unreliable or likely to relay disinformation. We argue that this circular transmission of information creates an "unreliable information bubble" that characterizes far-right information-sharing behavior.
\end{abstract}

Keywords: social media, political participation, ideological polarization, unreliable information, online activism

\footnotetext{
*Corresponding author: Julien Figeac, CNRS (French National Center for Scientific Research), LISST - University of Toulouse II, julien.figeac@univ-tlse2.fr.

Nikos Smyrnaios, LERASS - University of Toulouse III, nicolaos.smyrnaios@iut-tlse3.fr. Tristan Salord, IRIT - University of Toulouse III, tristan.salord@irit.fr.

Guillaume Cabanac, IRIT - University of Toulouse III, guillaume.cabanac@univ-tlse3.fr. Ophélie Fraisier, IRIT - University of Toulouse III, ophelie.fraisier@irit.fr.

Pierre Ratinaud, LERASS - University of Toulouse III, pierre.ratinaud@univ-tlse2.fr.

Fanny Seffusatti, LISST - University of Toulouse II, sef.fanny@gmail.com.
} 


\section{Introduction}

The question of the internet's effects on the democratic balance of societies was raised early in the technology's development, due to the anticipated extent of its political repercussions (Papacharissi, 2010). The history of the internet was written not only in scientific and military laboratories but also at the desks of hackers, who injected their own libertarian culture into it. Some authors even viewed this technology as a liberating tool, allowing citizens to experiment with more horizontal modes of social organization (Castells, 2002). Others, however, emphasized the fact that the internet did not necessarily foster confrontation with opposing points of view and did thus not fulfill this minimal condition for democratic deliberation. This controversy, now fueled by the proliferation of false information circulating within social media, led us to question the effects of these platforms on exposure to political information and polarization of opinions. We propose to investigate this phenomenon from the perspective of information-sharing on Facebook during the 2017 French presidential election.

\section{The question of social media as vectors of information pluralism}

Some researchers have highlighted how the internet can revitalize democracy by promoting debate (Shane, 2004), and by generating a pluralism of information favorable to the forming of enlightened opinions as it allows exposure to a wider range of ideas (Benkler, 2006). With social media, users have the opportunity to consume a wide variety of news items and to share and discuss them with others (Lee and Song, 2017). These platforms involuntarily expose users to a great diversity of news, which they may not have intended to discover or read themselves (Valeriani and Vaccari, 2016; Weeks, Lane, Kim, Lee, and Kwak, 2017). As this 'accidental' exposure to news and relevant political information becomes more and more frequent in social media, users perceive themselves to be well-informed about politics (Fletcher and Nielsen, 2018; Gil de Zúñiga, Weeks, and ArdèvolAbreu, 2017). Therefore, in the context of producing, sharing, and receiving digital information, there is a trend of exposure to sources of information and ideas that are increasingly ideologically heterophilic and diversified (Bakshy, Messing, and Adamic, 2015; Messing and Westwood, 2014).

In contrast to these analyses on the positive effects of the internet and social media with respect to information quality and diversity, other studies show that such a plethora of information generates a perverse effect by reducing the political horizons of those exposed to it. Recent research shows, paradoxically, how such 
'accidental' exposure to news in social media could be negatively associated with both political knowledge and political interest (Gil de Zúñiga and Diehl, 2019). The news found on social networks may contribute to a cynical response to politics among the users least aware of the consequences of such 'accidental' exposure to political content (Song, Gil de Zúñiga, and Boomgaarden, 2020). It thus appears that this type of consumption of news or political content has a negative influence on the process of forming opinions, convictions, and political decisions.

At the same time, faced with a multitude of sources, some internet users will inevitably select those with which they feel they will agree. This is especially the case during electoral periods, when users train their attention toward media that focus on the candidates they support (Iyengar and Hahn, 2009). This trend is similar to the one observed by Muntz (2002), who found that people often prefer to avoid exchanges about subjects that challenge their beliefs. From this point of view, instead of promoting diversity, online discussion spaces may form "echo chambers" in which individuals are exposed primarily to opinions concordant to their own, thereby reinforcing their initial convictions (Sunstein, 2009).

This phenomenon of selective exposure to information sources is nowadays reinforced by algorithms based on machine learning. Indeed, search engines and social media offer more and more personalized information according to algorithmic recommendations (Agichtein, Brill, and Dumais, 2006; Das, Datar, Garg, and Rajaram, 2007). These automatized processes of content recommendation integrate various data to prioritize certain types of information in a user's social media news feed. Pariser (2011), in his well-known argument, considers that personalization algorithms tend to create a "filter bubble" by selecting and relaying on a priority basis content shared by "friends" that users appreciate the most. Such algorithms foster an ideological segregation of information sources by inciting individuals to select content that has been filtered to reflect their own opinions (Flaxman, Goel, and Rao, 2016). This trend promotes the polarization of individuals' political positions; individuals constitute and organize homophilic relational circles that they feed with information and ideas matching their own ideological foundations (Sunstein, 2009).

\section{Does Facebook promote the ideological polarization of information-sharing behavior within political communities?}

The plurality of political information offered by the internet appears to vary depending on the convictions and the degree of commitment of political supporters. In addition to allowing access to those seeking information relating to the candidates they support, social media convey a diverse variety of articles to 
users' news feeds. This exposes users to new information that they otherwise would not necessarily have read. This involuntary exposure to information incites those who rarely consume print media to pay some attention to the news and keep up-to-date with current issues (Fletcher and Nielsen, 2018). Whether voluntary or not, this exposure to news, thanks to social media, confronts users with opinions that may be contrary to their own convictions. In this sense, these media resemble more traditional mainstream media, forming a social context in which people are faced with conflicting views (Muntz, 2002), which may lead them to change their minds.

But it appears that this phenomenon varies considerably, depending on the level of commitment of a candidate's political supporters; the practices of highly involved supporters differ from those who rarely use online discussion groups. Individuals who are least involved in politics tend to develop more open-minded practices and are more often in contact with material that conveys differing and conflicting points of view (Bond and Messing, 2015). In contrast, people who follow candidates on Twitter to stay updated and to relay the latest news have a higher level of political homophily (Colleoni, Rozza, and Arvidsson, 2014).

One area of related research in the United States focused on which political groups (conservative and/or liberal) were affected by this phenomenon and to what extent. Jamieson and Cappella (2008) showed, for example, that conservatives formed an echo chamber in the "Opinion" sections of the Wall Street Journal and the Fox News website, where they were able to express their ideas and reinforce their mutual political convictions without encountering too much contradiction. Other researchers have shown that, by contrast, left-leaning communities may represent those with the most rigid views (as liberal sympathizers are found to have fewer Facebook "friends" sharing content out of line with their ideological position, that is, content published by conservative newspapers). By comparison, conservatives tend to have networks of Facebook friends who, on the whole, share a greater amount of content from information sources that are considered as more moderate (Bakshy, Messing, and Adamic, 2015). Accordingly, the sources of information circulating on Facebook among liberals thus tend to be more in line with their own ideological positions and more homophilic on an ideological level. This reinforces the probability that such partisan users will be exposed to sources of information and Facebook pages that are more likely to reinforce their convictions. It is therefore around this analysis - on the sharing of information sources and their alignment (or lack thereof) with the ideological positions of various political communities - that researchers try to measure and evaluate the degree to which social media increase or decrease exposure to various opinions, and whether such media contribute to political polarization (Peterson, Goel, and Iyengar, 2017). 
Our research extends this line of inquiry in order to explore the hypothesis of political polarization on social media in the French context. Our investigation proposes to develop research previously structured around the bipartisan system in the United States by including centrist groups as well as those found on the far right or far left of the French political spectrum. To that end, we focused on five political communities: La France Insoumise (LFI, far-left); the Parti Socialiste (PS, left); La République En Marche (REM, centrist); Les Républicains (LR, right); and the Front National (FN, far-right). The method consists of analyzing content published on Facebook pages and within Facebook groups to which supporters of the principle candidates contributed, in order to evaluate the ideological diversity of information sources that they shared.

To achieve this goal, we analyze which political communities share the most information derived from sources aligned with their own ideological positions, in order to determine whether such communities develop information-sharing behavior likely to fortify their political convictions. More specifically, we examine two complementary ways of sharing information. In the first section of the results, we analyze news items shared by Facebook page administrators and followers from news websites (right-wing or left-wing press). And, in the second section, we analyze the "endo-citation" rate between Facebook pages within the same political community. In other words, the objective is to identify which political communities use the social media when organizing their exchanges of ideas according to a "circular circulation of information” (Bourdieu, 1996, p. 23). Do the page administrators determine the relevance and value of information based on its visibility and centrality within the other Facebook pages of their own political community? This "circular circulation of information" among Facebook pages affiliated to the same political party is an important factor to be taken into account, as "[t]his sort of mirror-game, reflecting one another, produces a formidable effect of mental closure” (Bourdieu, 1996, p. 27). Our two-step study of information-sharing behavior will allow us to establish whether certain French political communities tend to foster the polarization of opinion or even to create such phenomena as "echo chambers" (Jamieson and Cappella, 2008).

\section{Does Facebook promote the spread of unreliable information within political communities?}

This controversy, related to the plurality of information in social media and the way its platforms can promote the ideological polarization of opinion, has been recently and profoundly amplified by the "fake news" crisis. To understand the issues of the "fake news" crisis, it is important to define the term, as it is often 
overused and misused, especially in scientific articles (Tandoc, Lim, and Ling, 2017).

The first studies on the subject analyzed precise phenomena of disinformation on Twitter, such as the spread of scientific rumors linked to the discovery of the Higgs Boson particle (De Domenico, Lima, Mougel, and Musolesi, 2013) or to an earthquake in Haiti (Oh, Kwon, and Rao, 2010). These analyses of disinformation became more diversified following the 2016 presidential election in the United States, when research work evaluated the role of “fake news" in Trump's candidacy and rise to power. Unlike the earlier work, these studies did not focus on the spread of a particular rumor but rather on a set of rumors by exploiting thousands of pieces of false information identified by fact-checking sites. This more quantitative research perspective thus allowed researchers to measure how false information promoted Trump's candidacy, especially among his supporters (Allcott and Gentzkow, 2017). Research shows more precisely that the spread of disinformation on Twitter (Vosoughi, Roy, and Aral, 2018; Grinberg, Joseph, Friedland, Swire-Thompson, and Lazer, 2019) and Facebook (Guess, Nagler, and Tucker, 2019) is largely driven by individuals with strong political convictions and, more often, by Republican supporters over 65 years old.

This finding upholds research of "echo chambers" (Sunstein, 2009; Jamieson and Cappella, 2008) previously mentioned by highlighting how the spread of "fake news", and the controversy surrounding information plurality only concern certain, specific political supporters and political communities. The same phenomenon can be observed in France, as the spread of disinformation is effectively more pervasive on Twitter with right-wing (Les Républicains) and far right (FN) supporters (Gaumont, Panahi, and Chavalarias, 2018). We shall therefore expand on previous works dealing with the spread of "fake news" on Facebook by highlighting possible differences between political communities.

In order to analyze the spread of "fake news", Wardle and Derakhshan (2017) suggest defining the notion by distinguishing, in particular, "disinformation" (which refers to incorrect information deliberately produced to harm a person, a social group or a country) and "misinformation" (i.e., false information produced without the intention of being detrimental, whether by journalists or ordinary users of the internet). Taking such 'simple' misinformation into account is essential because it allows us to consider the role of journalistic sources that may have inadvertently relayed false information.

In this research, we analyze the propagation of potential sources of disinformation and misinformation, labelling them together as unreliable information by referencing the different types of sources (i.e., unreliable sources) that have published or shared this kind of content in the past (news websites, blogs, activists' websites, etc.). Our objective here is not to identify actual disinformation and 
misinformation propagation, as we do not examine the precise content shared in the Facebook groups of our sample, but the potential risk of dissemination of unreliable information derived by the use of specific sources. In order to identify these unreliable sources, we use a database ${ }^{1}$ that references unreliable French news websites which have been shown to publish disinformation or misinformation according to French fact-checkers and journalists.

\section{Research questions}

This article extends previous research in order to better understand whether the sharing of news among political communities on Facebook reinforces political polarization (RQ1) and the spread of unreliable sources of information (RQ2). To reach this goal, we have implemented a mixed-research method that allows us to analyze the exchange of information on Facebook. More precisely, we have analyzed how this social media platform was used by the predominant political communities in France to share information during the 2017 presidential campaign. We analyzed the diversity of information sources shared during this campaign and, whenever possible, the reliability and political affiliation of these sources.

Research Question 1 (RQ1): The first research question deals with the issue of political polarization found on the Facebook pages of French political communities. First, we wish to determine which political communities organize their exchanges around a larger number of sources that are non-aligned with their ideological positions and which, on the contrary, are likely to reinforce their political opinions by feeding their exchanges from sources whose political positions are more often aligned with their own (RQ1a; cf. the first section of the results). Second, we wish to determine the endo-citation rate between the Facebook pages of each political community of our sample (RQ1b; cf. the second section of the results). The aim is to identify which political communities use Facebook according to the aforementioned principle of "circular circulation of information" (Bourdieu, 1996).

Research Question 2 (RQ2): The second research question extends research on the dissemination of disinformation and misinformation by analyzing the spread of unreliable sources of information. The goal is to identify whether the number of unreliable sources, those that are most likely to convey false information, is more significant in certain political communities than others (RQ2a; cf. the first section of the results). In particular, we test the hypothesis that the

1 Cf. Décodex (https://www.lemonde.fr/verification/). 
spread of unreliable information on Facebook is more significant among rightwing and far-right supporters, as observed in information-sharing behavior on Twitter (Gaumont, Panahi, and Chavalarias, 2018).

\section{Presentation of the method and the data set}

\section{Delimitation of the perimeter of the Facebook data set}

This research analyzes how the main French political movements and their supporters used Facebook during the 2017 presidential election to exchange information and to foster debate. This analysis is based on records of usage collected between October 2016 and May 2017 from the Facebook pages of the leading French political communities. In defining the perimeter of this data set, we identified two main types of Facebook pages:

1. We looked up the parties' official Facebook pages (those having a national audience), followed by those published locally. These national pages are produced by community managers assigned to this position (page administrators), who are specifically responsible for managing the publication of content and regulating comments. We found it productive to measure the types of information sources they share, their ideological diversity (RQ1) and their reliability (RQ2).

2. There are also public groups created by activists, partisans, or citizens. We have attempted to evaluate the types $f$ sources they share, their ideological diversity (RQ1) and their reliability (RQ2).

We collected data from these two types of Facebook pages, targeting the most active communities on Facebook. Like previous works on the 2017 French political campaign (Gaumont, Panahi, Chavalarias, 2018; Fraisier, Cabanac, Pitarch, Besancon, and Boughanem, 2018), this study focused on the five predominant French political communities, those that supported the candidatures of: Jean-Luc Mélenchon, the leader of La France Insoumise (LFI), a political movement bringing together various political forces of the radical far-left; Benoit Hamon, who represented the French Parti Socialiste (PS) and the moderate left; Emmanuel Macron, the winner of the election, whose party La République En Marche (REM) unified the centrist political movement; François Fillon, who led the right-wing party Les Républicains (LR); and Marine Le Pen, the leader of the far-right Front National (FN), which is a growing political movement in France. 
We conducted 75 interviews with party supporters and community managers across these five political movements, having them cite the most important Facebook pages and to help us define our data set. At the end of this interview campaign, we identified the 252 most active Facebook pages and groups during the presidential campaign. These represent the primary, official pages and groups of the political parties at all three levels of the French territorial organization: national, regional, and departmental. In the end, this data set included approximately 50 pages and groups for each of the five political communities.

\section{Data analysis method}

We used Netvizz (Rieder, 2013) to extract posts which had been published on these Facebook pages and in the groups. This extraction allowed us to collect 1,146,784 posts, dating from October 2016 to May 2017. These posts shared different types of content (text, pictures, videos, etc.). $31 \%$ of these posts contained a link which redirected to a news article or, more generally, to a source of information outside Facebook. Our research deals exclusively with these posts. The other types of posting were those containing a simple Facebook status (31\%), a video (19\%), a photo hosted directly on Facebook (18\%), or an event (1\%). Our research does not take into account these latter types of publication.

Once the URLs for the shared content were obtained, we defined a protocol that would enable us to codify the data in order to answer our research questions. To reach this goal, we used and expanded the Décodex database developed by reporters working for the daily newspaper Le Monde. ${ }^{2}$ The aim of this journalistic initiative was to catalog the primary information sources circulating in the French public space and to classify them according to their reliability (Figueira and Oliveira, 2017; Venturini, Jacomy, Bounegru, and Gray, 2018). This entailed identifying and distinguishing reliable sources - those engaged in fact-checking or the journalistic task of verification - from unreliable or hardly reliable sources (those having relayed false information or disinformation in the past).

The Décodex offers a downloadable database that references the domain names and URLs of various information sources by classifying them as "reliable”, "rather reliable”, or "unreliable”. The Décodex also classifies information sources according to type (national newspaper, local newspaper, TV station, news website, blog, etc.) as well as indicating whether the referenced sources tend to lean, politically, toward the left or the right (this classification is not com-

2 Cf. the Décodex site: https://www.lemonde.fr/verification/ 
prehensive, as some sources are not categorized politically). With respect to the "type of source" criterion, we completed the Décodex classification manually, as the nomenclature of the Décodex was limited and did not reflect certain categories that were present in our sample, such as social media (e.g., YouTube, Twitter, etc.), surveys, cloud storage services (e. g., Dropbox), political institutions (e.g., parties), and service providers (e.g., Orange, SFR, Google News, Yahoo!).

We then reorganized the "reliability" classification by merging the "reliable" and "rather reliable" Décodex categories in order to obtain two basic categories of "reliable" (which corresponds to Décodex's "reliable" and "rather reliable") and "unreliable". We also reorganized the "type of source" classification, thus obtaining eight new categories: social media, press (containing all professional media, such as local, national and international press, web-based news outlets, TV, and radio websites), political institutions, activist websites, blogs and personal pages, opinion surveys, and cloud storage providers.

In order to focus on information having a significant impact on Facebook users, we decided to target sources that had more than 10 occurrences in our sample (i.e., sources whose domain names appeared more than ten times in the data we collected from all the Facebook pages and groups of our sample). Therefore, the manual categorization process focused on $95.04 \%(355,503)$ of the information sources in the dataset in order to record three complementary variables: the different types of information sources, their reliability, and their political affiliation (Table 1). Finally, we were able to code the types of information sources shared in $82.20 \%(n=292,210)$ of the individual URLs contained in our sample of Facebook publications. The categorization rates for the "reliability" score of these information sources is much lower (37.49\%) because it is not always possible to attempt to assess the reliability of certain sources (political institutions and activist websites, personal pages, and so on). Despite this lower rate, it should be considered that our analysis is based on a significant number of publications $(133,261)$. The same applies to the categorization of the political affiliation of various sources $(53,327)$, although here, too, the score is lower (15\%) because it is not always possible to specify whether a source is politically on the right or on the left. 
Table 1: Categorization scores of the information sources.

\begin{tabular}{|c|c|c|c|c|}
\hline & $\begin{array}{l}\text { Total } \\
\text { information } \\
\text { sources }\end{array}$ & $\begin{array}{l}\text { Types of } \\
\text { information } \\
\text { sources }\end{array}$ & $\begin{array}{l}\text { Reliability of } \\
\text { information } \\
\text { sources }\end{array}$ & $\begin{array}{l}\text { Political affiliation } \\
\text { of information } \\
\text { sources }\end{array}$ \\
\hline Categorization & 355,503 & 292,210 & 133,261 & 53,327 \\
\hline scores & $100 \%$ & $82.20 \%$ & $37.49 \%$ & $15.00 \%$ \\
\hline
\end{tabular}

We tested the reliability of the manual coding of the Facebook data by carrying out a Cohen's Kappa test (Cohen, 1960). This test consists in having three research scientists encode the same sample, randomly constituted, in order to measure how closely they agreed - that is, the number of times they attributed the same political affiliation to a URL. The result of the test was conclusive in that the score obtained was very high $(\kappa=0.959)$ and characteristic of an almost perfect match among the annotators.

\section{Results}

\section{The reliability and the ideological diversity of information sources shared within the different political communities.}

This section will describe the diversity and scope of the various types of information sources shared by French political communities during the 2017 presidential election. We shall then analyze the reliability of these sources according to their risk of conveying disinformation (RQ2). Then, the ideological diversity of these sources will be evaluated by measuring the proportion of right- and left-wing sources in each of these communities (RQ1).

Our results show that the large majority of content ( $42 \% ; 124,569$ posts) relayed within political communities comes from "Social media" (cf. Figure 1), mainly consisting of videos shared from YouTube or of posts shared from another Facebook page or group ( $23.37 \% ; 68,289$ posts). The "Press" category comes next (24\%; 71,577 posts) - newspaper websites, television channels, radio stations, and webbased media. Political institutions' websites are often shared, especially within LFI (19\%). FN stands out due to the prominent place given to content relayed from activists' websites (11\%) or blogs and personal pages (12\%). Among the other types of content, one can find "Opinion Surveys", material sourced from "Cloud and storage" (where photos and videos published on Facebook are frequently stored), and news content generated by service "Providers" (e. g., Google news). 


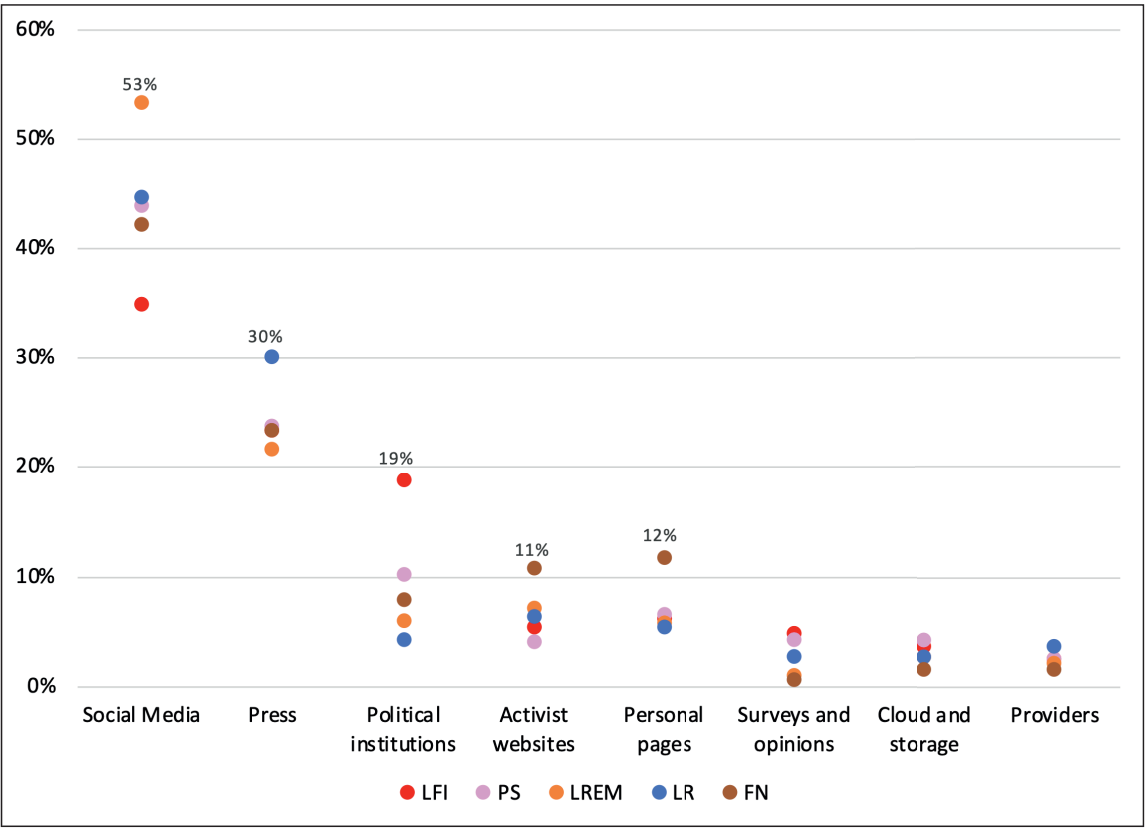

Figure 1: Types of information sources shared within political communities.

We will now examine the reliability of these sources according to the Décodex classification. It appears that $86.06 \%(114,679)$ of the content shared within our sample set has been shared from reliable sources (Table 2). More specifically, our data show that a majority of the political communities mostly shared articles and content from a wide range of sources that can be considered "reliable" (Figure 2). This trend of sharing reliable sources is most evident in the LFI and PS communities, as shown in the standardized residual analysis (Table 2). 


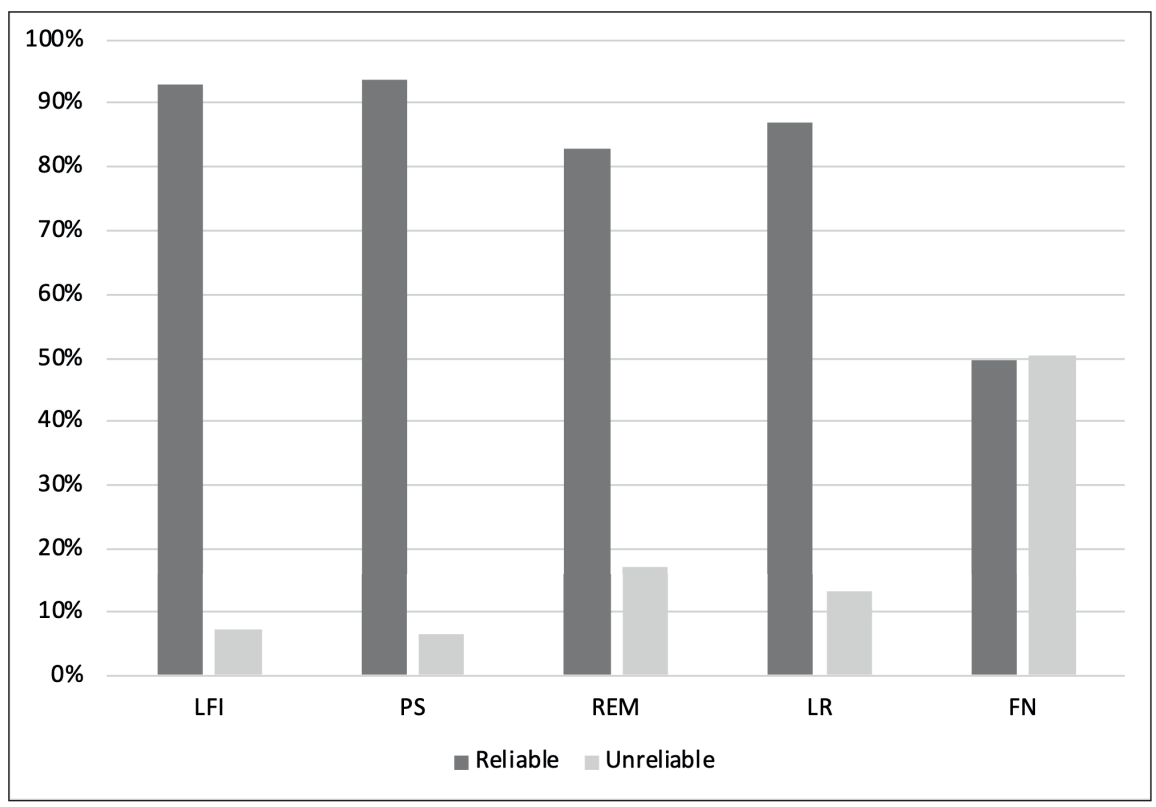

Figure 2: Reliability of information sources shared within political communities.

Table 2: Point-biserial correlation results.

\begin{tabular}{|c|c|c|c|}
\hline & & \multicolumn{2}{|c|}{ Reliability of information sources } \\
\hline & & Reliable & Unreliable \\
\hline \multirow{3}{*}{\multicolumn{2}{|c|}{$\begin{array}{l}\text { Political community } \\
\text { df } \\
\text { Cramer's V }\end{array}$}} & \multicolumn{2}{|c|}{$15614^{\star \star \star}$} \\
\hline & & \multicolumn{2}{|l|}{4} \\
\hline & & \multicolumn{2}{|c|}{0.342} \\
\hline \multirow{5}{*}{$\begin{array}{l}\text { Standardized } \\
\text { residuals }\end{array}$} & LFI & 63.2202 & -63.2202 \\
\hline & PS & 22.50277 & -22.50277 \\
\hline & REM & -16.90614 & 16.90614 \\
\hline & LR & 5.518151 & -5.518151 \\
\hline & FN & -117.6625 & 117.6625 \\
\hline \multicolumn{2}{|l|}{$N$} & 114679 & 18582 \\
\hline
\end{tabular}

Chi-square test: $\left.{ }^{*} p<.05 ;{ }^{* *} p<.01 ;{ }^{* * *} p<.001\right)$.

$d f$ : degrees of freedom.

Yet, what the standardized residuals analysis shows (cf. Table 2) is how the FN community stands out from the others with regard to its frequent reference to "unreliable" sources. "Alternative" information sites have a more prominent 


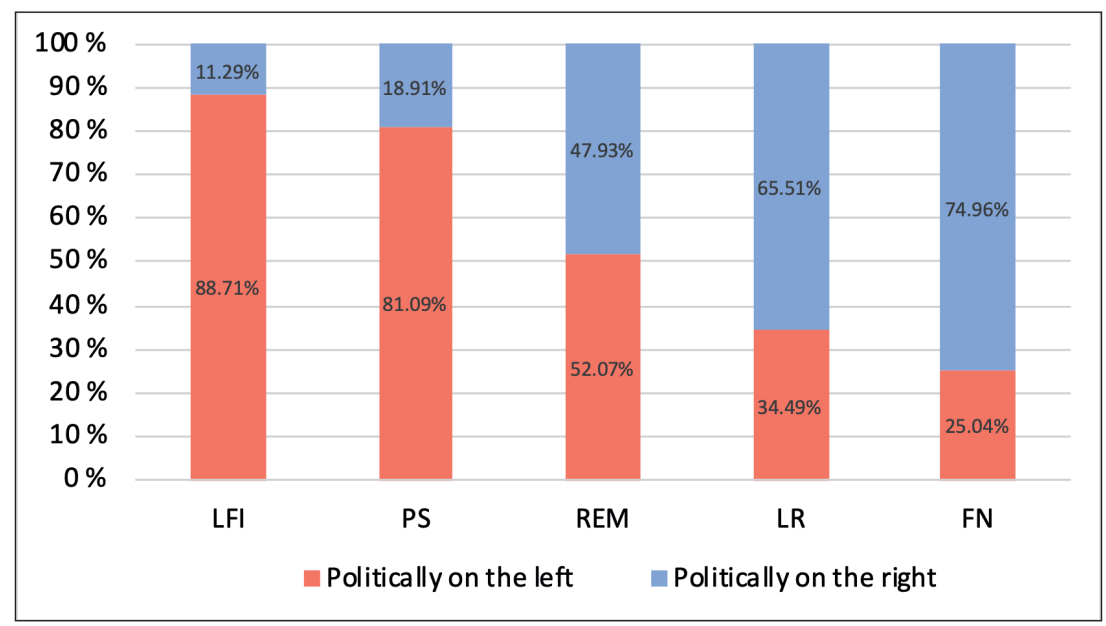

Figure 3: Political orientation of sources shared within political communities.

place in this community, particularly among the personal pages and activist groups identified as such in Figure 1. These sites share information using a particularly critical approach and a "counter-hegemonic" argumentative rationale (Pratt, 2004), the aim of which is to propose a counter-interpretation of current news, and to rebut analyses made by the mainstream press. Among these unreliable sources, we also find sites that the Décodex explicitly classified as far-right due to the publication of radicalized or hostile statements - toward Islam, for example - and which may already have been condemned by French courts for hate speech. Other than this aspect, the unreliable character of these sites lies in their tendency to implement disinformation, that is, to spread false information, to misrepresent reality in order to defend their private interests (or those of the political candidate they support), or to harm others. As a candidate, Emmanuel Macron frequently came under direct attack and as a result of information relayed by these sources. During interviews, REM supporters explained that they had to counter such slander campaigns by criticizing these articles, which contained false information. To do so, they had to share the articles themselves, which is one possible explanation for the large number of fairly unreliable information sources that circulated within the REM community.

It is interesting to complete this source reliability (RQ2) analysis with an analysis of the various parties' degree of exposure to sources aligned or non-aligned with their own ideological positions (RQ1). Figure 3 below shows that those associated with the centrist party (REM) share articles published by "right-wing" and "left-wing" media on an almost equal basis. 
Centrists aside, a clear overrepresentation of sources corresponding to group members' own political orientations can be observed among the other political groups (cf. Figure 3 and Table 3). This trend is heightened among the LFI (88.71\%), who share very little information published by media with an opposing political orientation (this result is confirmed by the standardized residual analysis (Table 3). The same can be said of the FN (74.96\%) but to a slightly lesser extent.

Table 3: Point-biserial correlation results.

\begin{tabular}{lccc}
\hline & \multicolumn{2}{c}{ Political orientation of sources } \\
\cline { 3 - 4 } & & Left & \multicolumn{2}{c}{ Right } \\
\hline $\begin{array}{l}\text { Political community } \\
\text { df }\end{array}$ & \multicolumn{2}{c}{$13707^{\star \star \star}$} \\
Cramer's V & \multicolumn{3}{c}{4} \\
\hline Standardized & LFI & 101.2241 & -101.2241 \\
residuals & \multicolumn{3}{c}{} \\
& PS & 14.01024 & -14.01024 \\
& REM & -42.77439 & 42.77439 \\
& LR & -85.90143 & 85.90143 \\
& FN & -38.90641 & 38.90641 \\
\hline$N$ & & 38213 & 15114 \\
\hline
\end{tabular}

Chi-square test: $\left.{ }^{*} p<.05 ;{ }^{* *} p<.01 ;{ }^{* * *} p<.001\right)$.

df: degrees of freedom.

These results thus show a distinct correlation between the degree of exposure to ideologically opposed sources and the position these communities occupy on the political map. The more that political sympathizers defend ideas and programs far from centrist positions (those that are relayed the most by media classified as "mainstream" by Décodex), the less is their degree of exposure to sources nonaligned to their own political views.

Drawing from previous research (Bakshy, Messing, and Adamic, 2015), we can equally note that the community traditionally ranked as the farthest right of the political spectrum (LR) is exposed to more sources non-aligned with their own ideological positions (34.49\%) than the community (PS) traditionally ranked as the leftmost (18.91\%; cf. Figure 3). This can be explained, in France as in other countries, by the large number of media produced by professional journalists who are classified as "politically on the left" in the Décodex database. This larger number of sources that are generally seen as left-wing explains why right-wing and far-right supporters are structurally more exposed, whether voluntarily or not, to information sources that lean more to the left. 


\section{The endo-citation phenomenon on Facebook pages of a same political community}

In the posts to Facebook published by the French political communities during the 2017 presidential campaign (1,146,784 publications in our data set), we have shown that $31 \%$ contain a link to a source of information external to Facebook (a press site, a blog article, etc.). In the previous section, Figure 1 shows that $42 \%$ of these publications $(124,569)$ were shared from another social media platform (Twitter, Instagram, etc.) or, notably, from another Facebook page $(23.37 \%$; 68,289 publications). Since a large amount of shared information on Facebook pages comes from other Facebook pages, we have analyzed this information flow within the Facebook pages of the different communities in order to evaluate their ideological diversity (RQ1b) and their reliability (RQ2). We shall qualify this as an endo-citation phenomenon.

In our approach, we started by identifying the types of sources, in this case the types of Facebook pages, that are cited most frequently. It seems that the content relayed internally comes most often from other public pages or other public groups (cf. Figure 4). Their portion is significantly lower in LR communities since the information there is more often shared from content published on personal pages. The same is true for the FN, for which the personal pages are more central, notably due to the important role played by the party leaders, especially Marion Maréchal-Le Pen and Florian Philippot.

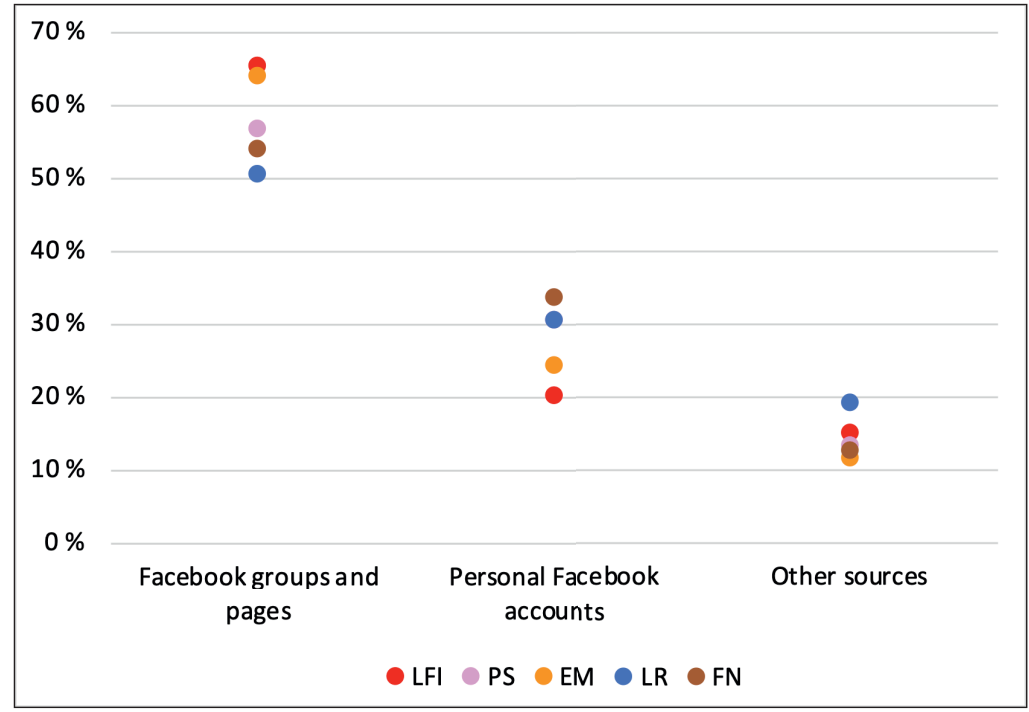

Figure 4: Origin of publications shared internally on Facebook. 
Figure 5 analyzes more precisely the origins of the Facebook pages from which the content was drawn. This analysis appears here for each political community. It first shows that pages produced by parties and political movements on the far left or far right of the political map (LFI and FN) tend to relay a vast amount of content published by other Facebook pages affiliated with their own political movement. In $96 \%$ of the cases, pages produced by the FN community relayed content that was initially shared on other far-right pages. The endo-citation rate between LFI-associated pages and other far-left pages is $93 \%$. This rate is equally quite high in the LR community (84\%). It is slightly lower among pages in the PS
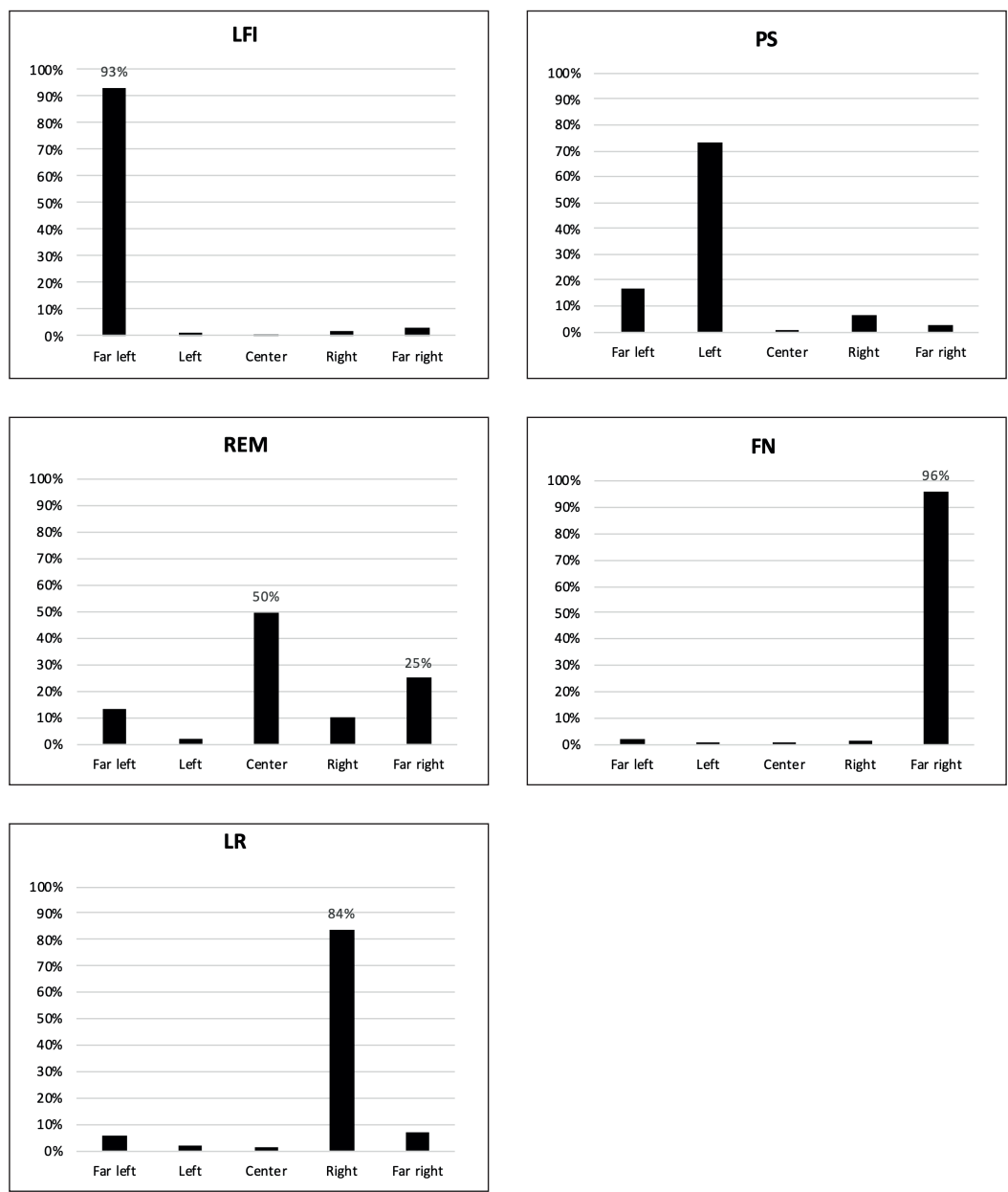

Figure 5: Political affiliation of the Facebook pages (public groups or public pages). 
community (74\%), which took content more often from farther left-wing pages. This latter result should be interpreted with caution, since we are unable to determine whether these contents were relayed to express shared approval or if, on the contrary, the PS admins relayed posts from the far-left pages in order to criticize them. Likewise, it is possible that the large number of posts $(25 \%)$ shared by the REM and taken from pages associated with the far right were indeed used to criticize their content. This claim was made by the REM Facebook page managers during our interviews. According to them, the purpose of such cross-posting was essentially to counter attacks on Emmanuel Macron which they considered slanderous.

The highest endo-citation rates of the FN and the LFI, and to a lesser degree of the LR, show to what extent social media can be used by party supporters and political movements to develop an information-sharing environment that is deeply homophilic from an ideological point of view. Only the REM pages took a significant amount of information non-aligned with their ideological positions by transmitting material that was published on pages linked to the far right $(25 \%$; Figure 5) or the far left (13\%). But, generally speaking, the aim of sharing politically opposed news sources was to criticize them.

Even if these endo-citation rates reveal a very partial rationale for the sharing of information, they should nevertheless be interpreted with caution. We should recall and fully take into account the impact of the result of the preceding section. Since the FN community pages share a much greater amount of content published by fairly unreliable sources (cf. Figure 2 and Table 2), it seems obvious that such unreliable content is at the heart of the endo-citation phenomenon seen on the community's own Facebook pages. Inversely, as the LFI community is that which, along with the PS, shares the largest number of reliable sources, it seems equally obvious that such verified content, corresponding to credible journalistic work, is of central importance to this political community. In other words, if communities tend to form echo chambers, in which information in line with their own political positions is circulated ad infinitum, this information circulated by the left remains nevertheless rather reliable in spite of its eventual critical or "counter-hegemonic" scope. If the high endo-citation rates of the LFI and LR communities reflect an information-sharing mode characteristic of an echo chamber, it absolutely does not reflect a phenomenon of opinion-polarization organized around a large proportion of unreliable information. Only the FN community reflects this type of information bubble, in which numerous "counter-hegemonic" materials circulate (Downing, 2000; Pratt, 2004); the authors of such materials are not merely opposed to what is perceived as the dominant ideology (as LFI supporters are), but they also attempt to counter it through disinformation, in order to defend their interests or to malign stigmatized communities. 


\section{Discussion and conclusion}

This research analyzes how the main French political communities used Facebook to exchange information during the 2017 presidential campaign. The practices described here are those implemented by community managers to drive the campaigns of the candidates they supported via Facebook. The idea was to analyze the types of information published by political communication specialists as well as those that were shared or liked - on an individual, reflexive, and less strategic scale - by users, especially by participants in public Facebook groups.

This research illustrated a wide variety of information sources circulating in social media. It also revealed to what extent Facebook competes with news outlets, by allowing its activist users to relay other types of information, notably that published by political movement websites or personal blogs, in order to debate policy or to stage candidates' campaigns.

We then tried to comprehend better the effects of this diversification of information-type by questioning source reliability (RQ2). Our results led us to highlight the information practices of the Front National community due to a clear overrepresentation of "unreliable" sources, those that were most likely to relay misinformation or disinformation.

The next objective was to evaluate the ideological diversity of these sources (RQ1). We have shown that most of the parties and political movements, particularly those found on the extreme ends of the political spectrum, tend to share a large amount of information published by daily newspapers or magazines with the same ideological position as their own. This becomes even more apparent when the degree of endo-citation within Facebook pages is analyzed, as members of a political community very often share contents published on the pages of other members within that community. This environment is organized according to a phenomenon of "circular circulation of information" that produces a "formidable effect of mental closure" (Bourdieu, 1996). We can indeed consider that on Facebook, the logic of endo-citation between pages of the same political community creates this phenomenon of mental closure. In this sense, these findings thus underpin the idea that such debate arenas, and the information-sharing behavior found therein, tend to be organized with a rationale that is characteristic of social grouping, deeply homophilic from an ideological point of view, and likely to polarize opinions and reinforce political convictions.

Yet is it not the purpose of these Facebook pages to try and arouse the greatest number of sympathizers to adhere to party convictions and to vote for a specific candidate? Probably. Even if our results confirm a fact that was logically predictable (given the way in which activists have used political blogs until today), our research has gone even further. It shows that one must take into account the 
degree of reliability of the information circulating in a loop within social media. That is why we consider that the discovery of overrepresentation of fairly unreliable sources within the far right sheds new light on this phenomenon of ideological opinion-polarization and differentiates the far-right community from the types of information-sharing behavior observed in the other political communities. We consider that this phenomenon observed within the FN community can be qualified as an "unreliable information bubble".

This is the main contribution of our article, which comes in response to a current research inquiry regarding the specificity of the phenomenon of ideological polarization assembled on Facebook by extremist political groups (Bond and Messing, 2015). Far-right practices stand out in our analyses. Unlike conservatives in the United States (Jamieson and Cappella, 2008), it is more difficult for French far-right groups to conduct their discussion in the mainstream media forums. They do not have the power to maintain frameworks for debate which are both aligned with their own ideological position and also oriented toward the editorial line of these mainstream media (Boutyline and Willer, 2017), as subscribers to the online version of the newspaper Le Monde tend to do in their frequent and occasionally politically-oriented engagement. The radicalism of FN sympathizers' opinions leads them to occupy online discussion spaces that are more exclusive, and also unreferenced by search engines, such as Facebook groups, which are frequently used by internet users with similar political convictions. There they can debate "counter-hegemonic" subjects (Downing, 2000; Pratt, 2004) that are not covered by the press; they can analyze social issues over and above the ideological spectrum of mainstream media analyses. Their desire for critical, even radicalizing, information leads such users to share contents from one Facebook page to another in order to enliven their exchanges. Through this digital participation, the most active partisans attempt to develop a publicity model - one that competes with that dominated by television - in order to access the public space and defend or advocate for their own political convictions (Dayan, 2009). It is this desire for a radicalized sort of social criticism, and a willingness to share such criticism on a larger scale, that leads sympathizer networks to create "unreliable information bubbles" on Facebook.

The challenge now consists of understanding better to what extent exposure to these counter-hegemonic theses via social media, especially when such exposure is ephemeral and involuntary, can palpably influence individuals' political participation, particularly among the youth and those who do not read the most trustworthy press. We should thus be able to better comprehend whether the pluralism of information offered by the internet fosters the propagation of populist opinions, thereby tending to accentuate the crisis in our democracy. 
Acknowledgement: The French National Research Agency generiously supported this research (The Listic project - ANR-16-CE26-0014-0).

\section{References}

Agichtein E., Brill, E., \& Dumais, S. (2006). Improving web search ranking by incorporating user behavior information. In Proceedings of the $29^{\text {th }}$ annual international ACM SIGIR conference on research and development in information retrieval, 19-26, ACM.

Allcott, H., \& Gentzkow, M. (2017). Social media and fake news in the 2016 election. Journal of Economic Perspectives, 31(2), 211-36.

Bakshy, E., Messing, S., \& Adamic, L. A. (2015). Exposure to ideologically diverse news and opinion on Facebook. Science, 348(6239), 1130-1132.

Benkler (2006). The wealth of networks: How social production transforms markets and freedom. Yale: Yale University Press.

Bond, R., \& Messing, S. (2015). Quantifying social media's political space: Estimating ideology from publicly revealed preferences on Facebook. American Political Science Review, 109(1), 62-78.

Bourdieu, P. (1998[1996]). On television. New York: The New Press.

Boutyline, A., \& Willer, R. (2017). The social structure of political echo chambers: Variation in ideological homophily in online networks. Political Psychology, 38(3), 551-569.

Castells, M. (2002). The internet galaxy: Reflections on the internet, business, and society. Oxford University Press on Demand.

Cohen, J. (1960). A coefficient of agreement for nominal scales. Educational and Psychological Measurement, 20(1), 37-46.

Colleoni, E., Rozza, A., \& Arvidsson, A. (2014). Echo chamber or public sphere? Predicting political orientation and measuring political homophily in Twitter using big data. Journal of Communication, 64(2), 317-332.

Das, A. S., Datar, M., Garg, A., \& Rajaram, S. (2007). Google news personalization: Scalable online collaborative filtering. In Proceedings of the $16^{\text {th }}$ international conference on World Wide Web, 271-280, ACM.

Dayan, D. (2009). Sharing and showing: Television as monstration. The Annals of the American Academy of Political and Social Science, 625(1), 19-31.

De Domenico, M., Lima, A., Mougel, P., \& Musolesi, M. (2013). The anatomy of a scientific rumor. Scientific Reports, 3, 2980.

Downing, J. D. (2000). Radical media: Rebellious communication and social movements. Sage.

Figueira, Á., \& Oliveira, L. (2017). The current state of fake news: Challenges and opportunities. Procedia Computer Science, 121, 817-825.

Flaxman, S., Goel, S., \& Rao, J. M. (2016). Filter bubbles, echo chambers, and online news consumption. Public Opinion Quarterly, 80(S1), 298-320.

Fletcher, R., \& Nielsen, R. K. (2018). Are people incidentally exposed to news on social media? A comparative analysis. New Media \& Society, 20, 2450-2468. 
Fraisier, O., Cabanac, G., Pitarch, Y., Besancon, R., \& Boughanem, M. (2018). \# Élysée2017fr: The 2017 French Presidential Campaign on Twitter. In Twelfth International AAAI Conference on Web and Social Media.

Gaumont, N., Panahi, M., \& Chavalarias, D. (2018). Reconstruction of the socio-semantic dynamics of political activist Twitter networks - Method and application to the 2017 French presidential election. PLOS ONE 13, e0201879.

Gil de Zúñiga, H., \& Diehl, T. (2019). News finds me perception and democracy: Effects on political knowledge, political interest, and voting. New Media \& Society, 21(6), 1253-1271.

Gil de Zúñiga, H., Weeks, B., \& Ardèvol-Abreu, A. (2017). Effects of the news-finds-me perception in communication: Social media use implications for news seeking and learning about politics. Journal of Computer-Mediated Communication, 22, 105-123.

Grinberg, N., Joseph, K., Friedland, L., Swire-Thompson, B., \& Lazer, D. (2019). Fake news on Twitter during the 2016 US presidential election. Science, 363(6425), 374-378.

Guess, A., Nagler, J., \& Tucker, J. (2019). Less than you think: Prevalence and predictors of fake news dissemination on Facebook. Science advances, 5(1), eaau4586.

lyengar S., \& Hahn, K. S. (2009). Red media, blue media: Evidence of ideological selectivity in media use. Journal of Communication, 59(1), 19-39.

Jamieson, K. H., \& Cappella, J. N. (2008). Echo chamber: Rush Limbaugh and the conservative media establishment. Oxford University Press.

Lee, J., \& Song, H. (2017). Why people post news on social networking sites: A focus on technology adoption, media bias, and partisanship strength. Electronic News, 11(2), $59-79$.

Messing, S., \& Westwood, S. J. (2014). Selective exposure in the age of social media: Endorsements trump partisan source affiliation when selecting news online. Communication Research, 41(8), 1042-1063.

Muntz, D. C. (2002). Cross-cutting social networks: Testing democratic theory in practice. American Political Science Review, 96(1), 111-126.

Oh, O., Kwon, K. H., \& Rao, H. R. (2010). An exploration of social media in extreme events: Rumor Theory and Twitter during the Haiti earthquake 2010. Icis, 231, 7332-7336.

Papacharissi, Z. A. (2010). A private sphere: Democracy in a digital age. Cambridge: Polity Press.

Pariser, E. (2011). The filter bubble: What the internet is hiding from you. London: Penguin UK.

Peterson, E., Goel, S., \& Iyengar, S. (2017). Echo chambers and partisan polarization: Evidence from the 2016 presidential campaign. Working paper.

Pratt, N. (2004). Bringing politics back in: Examining the link between globalization and democratization. Review of International Political Economy, 11(2), 311-336.

Rieder, B. (2013). Studying Facebook via data extraction: The Netvizz application. In Proceedings of the $5^{\text {th }}$ annual ACM web science conference, 346-355, ACM.

Shane, P. M. (Ed.) (2004). Democracy online: The prospects for political renewal through the internet. Routledge.

Song, H., Gil de Zúñiga, H., \& Boomgaarden, H. G. (2020). Social media news use and political cynicism: Differential pathways through “news finds me” perception. Mass Communication and Society, 23(1), 47-70.

Sunstein, C. R. (2009). Going to extremes: How like minds unite and divide. Oxford University Press.

Tandoc Jr., E. C., Lim, Z. W., \& Ling, R. (2017). Defining “fake news”. A typology of scholarly definitions. Digital Journalism, 6(2), 137-153. 
Valeriani, A., \& Vaccari, C. (2016). Accidental exposure to politics on social media as online participation equalizer in Germany, Italy, and the United Kingdom. New Media \& Society, 18, 1857-1874.

Venturini, T., Jacomy, M., Bounegru, L., \& Gray, J. (2018). Visual network exploration for data journalists. In S. Eldridge II, \& B. Franklin (Eds.), The Routledge Handbook to Developments in Digital Journalism Studies. Abingdon: Routledge.

Vosoughi, S., Roy, D., \& Aral, S. (2018). The spread of true and false news online. Science, 359(6380), 1146-1151.

Wardle, C., \& Derakhshan, H. (2017). Information disorder: Toward an interdisciplinary framework for research and policymaking. Council of Europe report, DGI (2017), 9.

Weeks, B. E., Lane, D. S., Kim, D. H., Lee, S. S., \& Kwak, N. (2017). Incidental exposure, selective exposure, and political information sharing: Integrating online exposure patterns and expression on social media. Journal of Computer-Mediated Communication, 22, 363-379. 